\title{
Note on the value of Frenzel's glasses for the recognition and qualitative evaluation of spontaneous nystagmus
}

\author{
H. H. TSCHANG AND M. SPENCER HARRISON \\ From the National Hospital, Queen Square, London
}

SUMMARY Spontaneous nystagmus encountered in neuro-otological practice is nearly always a physical sign of high diagnostic importance. Its localizing value is largely determined by certain $s$ of its qualitative characteristics and these are best studied and evaluated by means of the electro- ? nystagmograph, but for reasons discussed this is not suitable for use in smaller clinics. For the $\vec{\omega}$ recognition and qualitative analysis of spontaneous nystagmus the use of Frenzel's glasses used in complete darkness, as recommended by Frenzel himself, has been found to give very satisfactory results.

Nothing is more important in the course of a neuro-otological investigation than the examination for the presence of spontaneous nystagmus, and, when present, the evaluation of certain of its characteristics upon which its localizing value is dependent.

Thus, it has been known since the time of Barany that spontaneous nystagmus due to a peripheral vestibular lesion is inhibited by visual fixation. When, by contrast, the nystagmus is due to a central lesion, the matter is otherwise, and Gordon Holmes (1917), speaking of cerebellar nystagmus, describes its inhibition when visual fixation is removed.

In the course of the last two decades electronystagmography has played an important part in the clarification of this complex field. Certain technical aspects of this now well-established mode of investigation are of importance and Hallpike and his collaborators (Dix, Hallpike, and Hood, 1963; Dix and Hallpike, 1966; Hallpike, 1967) have stressed the advantage of using distortion-free recording systems, so making possible the accurate recording, not only of the nystagmic oscillations but also of sustained conjugate deviations of the eyes. These arise from the operation of a variety of central mechanisms and, as exemplified by Alexander's law, exert profound effects upon the nystagmus.

The neuro-otological situations in which nystagmography is of especial value may be briefly reviewed as follows:
1. NYSTAGMUS DUE TO UNILATERAL LESIONS AFFECTINC PERIPHERAL ELEMENTS OF ONE OR OTHER EXTERNA $\Phi$ CANAL Such a lesion may affect the canal end organs, as in Ménière's disease, or the canal ner@e fibres at any point of their extra- or intramedullar $\vec{\omega}$ course (Harrison, 1969). Its effect is to reduce of $د$ abolish the spontaneous resting discharge carried by the nerve, and the nystagmus, with its rapid component directed towards the unaffected ear, results from the unbalanced effect of the 'spontaneous' discharge from the opposite canal. For $\frac{\circ}{\mathbb{D}}$ this reason, Hallpike (1967) has suggested that it be designated a 'canal imbalance nystagmus'. Such a $\overrightarrow{\overrightarrow{0}}$ nystagmus is very marked immediately after the 3 destruction for Ménière's disease of a labyrinth in which some function of the external canal is retained, or, in the same situation after extracranial section of the vestibular nerve. It follows that after such an operation the occurrence of this variety of nystagmus provides important evidence that the purpose of the operation has been achieved. The nystagmus is not $\delta$ permanent. In the course of a few months - often $₹$ less-the associated vestibular centres of the 을 brain-stem, being deprived of the normal incoming nervous discharges, seem to establish a spontaneous activity of their own. In this way the outputs of the two vestibular centres-left and right-are brought or into balance and the nystagmus disappears.

The effect on a canal imbalance nystagmus of $\mathrm{N}$ visual fixation is very marked, and is most clearly 362 
studied under the conditions which obtain with electronystagmography. Here, a switch from light to darkness or vice versa causes an instantaneous abolition or restoration of fixation. The effects on the nystagmus are immediate and easily discerned. The examination is particularly revealing if carried out when the nystagmus is at a particular stage-that is, when it is completely inhibited in the presence of fixation, and appears only when this is abolished.

2. 'CENTRAL' NYSTAGMUS This results from organic derangement of a variety of brain-stem mechanisms which control the conjugate deviation of the eyes in the horizontal plane. The lesion may be situated within the brain-stem and is then usually neoplastic or demyelinating in nature. Alternatively, it may be situated outside the brain-stem, and, as in the case of an acoustic neurofibroma, produces nystagmus by pressure upon the brain-stem mechanisms in question.

The nystagmus is typically made manifest by voluntary conjugate deviation of the eyes towards visual fixation points to the left and/or right of the straight ahead line. On the elimination of fixation, the eyes tend to return towards the straight ahead line and the nystagmus disappears. If the lateral deviation of the eyes be maintained by means of voluntary effort the nystagmus is again observed but in a slower and less regular form. The nystagmus seems to depend essentially upon some weakness of the brain-stem mechanisms which subserve the maintenance of conjugate deviations of the eye, and for this reason Hallpike (1967) has suggested that it should be designated the "deviation maintenance' type of nystagmus. With this type of nystagmus, too, nystagmography using distortionfree recording is of the greatest diagnostic value.

In spite of the manifest advantages of this kind of equipment for the differential diagnosis of these, the two main types of spontaneous nystagmus, something must unfortunately be added about the practical difficulties which attend its use. It is expensive and requires for its proper maintenance and operation a laboratory of substantial size, well equipped, and with an expert technical staff. In larger centres this is, of course, a possibility and here there can be no doubt that electronystagmography with its valuable provision of permanent records has come to stay. There can be no doubt, too, that with continued technical improvements we may expect the equipment to become progressively cheaper and easier to use. Until this occurs, however, its use in smaller clinics is not a practicable possibility, a situation which, in view of the clinical importance of the matters concerned, must be counted a matter for serious regret.
To some extent these difficulties can be overcome by the use of Frenzel's well-known glasses, and Jongkees (1969) in a recent review has emphasized their value when used by experienced clinicians. We have carried out a comparative study of electronystagmography and Frenzel's glasses in evaluating the qualitative characteristics of spontaneous nystagmus in a series of patients. It is the purpose of this note to describe our findings.

Frenzel first described his Leuchtbrille in 1928. Visual fixation on surrounding objects is inhibited by means of strong + ve lenses (15-20D) and the light from small electric bulbs mounted between the lenses and the eyes. This light also illuminates the eyes for inspection under the magnification provided by the lenses. With normal room illumination some degree of visual fixation on surrounding objects is still possible but this we have found can be substantially reduced if the examination is carried out as prescribed by Frenzel himself with the room in darkness. Used in this way, the glasses have been systematically applied to the evaluation of the characteristics of nystagmus in a number of typical cases and in some the data obtained have been compared with those derived from electronystagmographic recordings. A brief selection of our findings will be described.

\section{CASE 1}

K.C., aged 53, complained of continued vertigo after right vestibulotomy (oval window approach) for Ménière's disease carried out four years previously. On examination with Frenzel's glasses, first degree nystagmus to the right was found to be present, resulting, it was considered, from an irritative lesion of the right labyrinth arising from its incomplete destruction. An electronystagmographic recording of the nystagmus is shown in Fig. 1. A second operation was accordingly performed at which the vestibular area of this labyrinth was completely exenterated.

After this, spontaneous nystagmus to the left appeared. It was marked at first and later subsided. In Fig. 2 are shown some electronystagmographic records taken two months after operation. It will be noted that the first degree nystagmus to the left recorded with Frenzel's glasses is only slightly less than that recorded in darkness. It could, moreover, be detected readily and its characteristics evaluated by visual observation through the glasses.

\section{CASE 2}

G.C., aged 35. Left acoustic neurofibroma with involvement of the brain-stem was confirmed at operation. There had been an acute onset, three years previously, of rotational vertigo with nausea and vomiting followed by persistent unsteadiness and tendency to fall to the left. Also, left deafness and tinnitus had been present for 

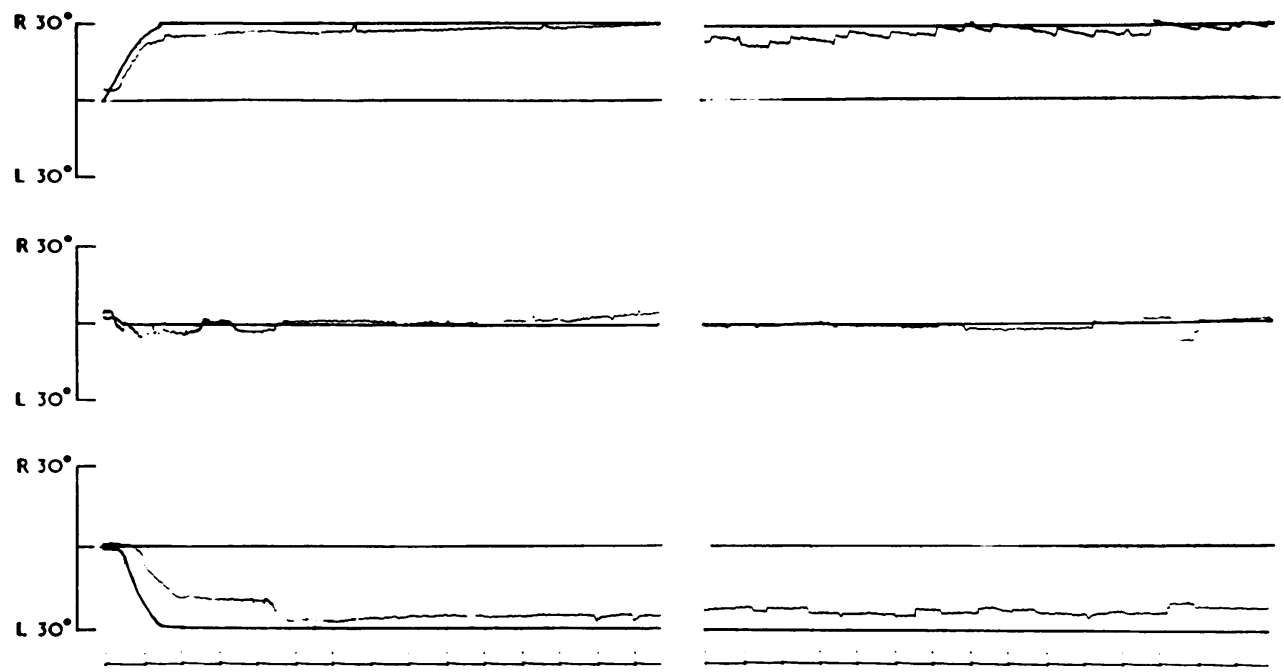

FIG. 1 Ménière's disease. Subject K.C. Incomplete right labyrinthectomy four years previously. Electronystagmographic tracings on the left (recorded in the presence of visual fixation) showed absence of spontaneous nystagmus; the tracings on the right (recorded in darkness) showed first degree spontaneous nystagmus to the right. Time scale in seconds.

VISUAL FIXATION
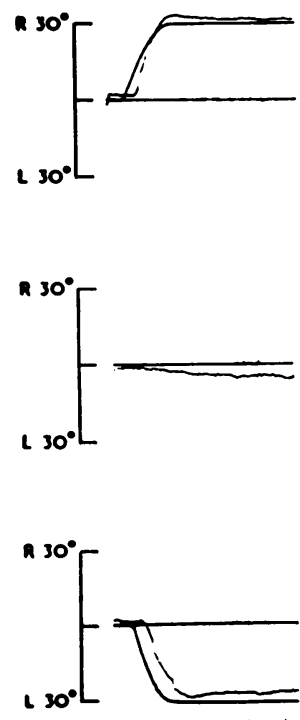

FRENZEL'S GLASSES
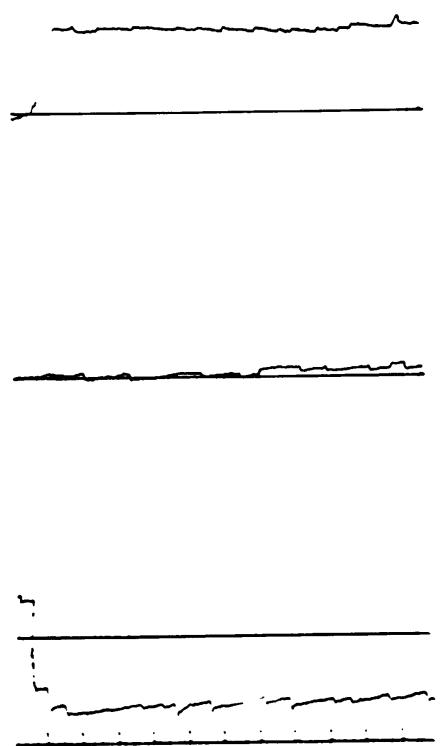

DARKNESS
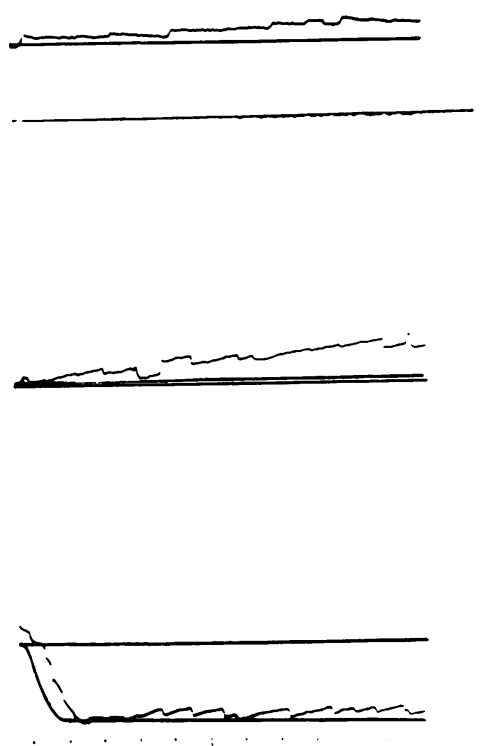

FIG. 2 Ménière's disease. Subject K.C.Two months after revision of right vestibulotomy. Electronystagmographic tracings on the left (recorded in the presence of visual fixation) showed absence of spontaneous nystagmus; the tracings in the middle (recorded using Frenzel's glasses in darkness) showed first and second degree spontaneous nystagmus to the left; the tracings on the right (recorded in darkness) showed first and second degree spontaneous nystagmus to the left. Time scale in seconds. 
one year. On examination, there was slight hypofunction of left trigeminal and facial nerves. Left perceptive deafness with reversal of loudness recruitment was present. Spontaneous nystagmus was noted. Electronystagmograph recordings of this are shown in Fig. 3.

It will be seen from the records that the first degree nystagmus to right and left is of the so-called deviation maintenance type-that is, with visual fixation maintained, it is regular and well maintained. With visual fixation reduced or abolished then, provided that the conjugate deviations of the eyes are maintained, as shown on the records, by voluntary effort, the nystagmus continues. Its character changes, however, and it becomes irregular, slower, and of greater amplitude.

As in case 1, these qualities of the nystagmus, so evident from the records, could also be recognized quite satisfactorily and evaluated from visual observation of the eyes through the lenses of Frenzel's glasses.

Reference will also be made to two other cases representative of situations in which Frenzel's glasses have been of notable value.

\section{CASE 3}

H.C., aged 36, had had 'black-outs' of unknown cause for nine years. Severe bilateral reduction of caloric responses was found with normal hearing. The provisional diagnosis was vestibular neuronitis. The possibility was also considered that the severe reduction of the caloric responses was due, not to any organic vestibular lesion, but to the suppression of the responses by hyperactivity of the visual fixation mechanisms. This was confirmed by the finding of apparently normal caloric responses when the tests were repeated with Frenzel's glasses.

\section{CASE 4}

C.F.W., aged 56 complained of transient giddy attacks on lying back in bed or on looking up, for 10 years. Hearing was normal. Caloric responses were brisk with directional preponderance to the left. No spontaneous or positional nystagmus could be observed, at any rate when the test for the latter was carried out, as usual, with visual fixation maintained. When, however, the test was repeated with Frenzel's glasses it was possible, with the patient's head back and to the left, to observe some typical positional nystagmus of the so-called benign paroxysmal type attributable in all probability to a chronic lesion of certain of the sense organs of the left labyrinth.
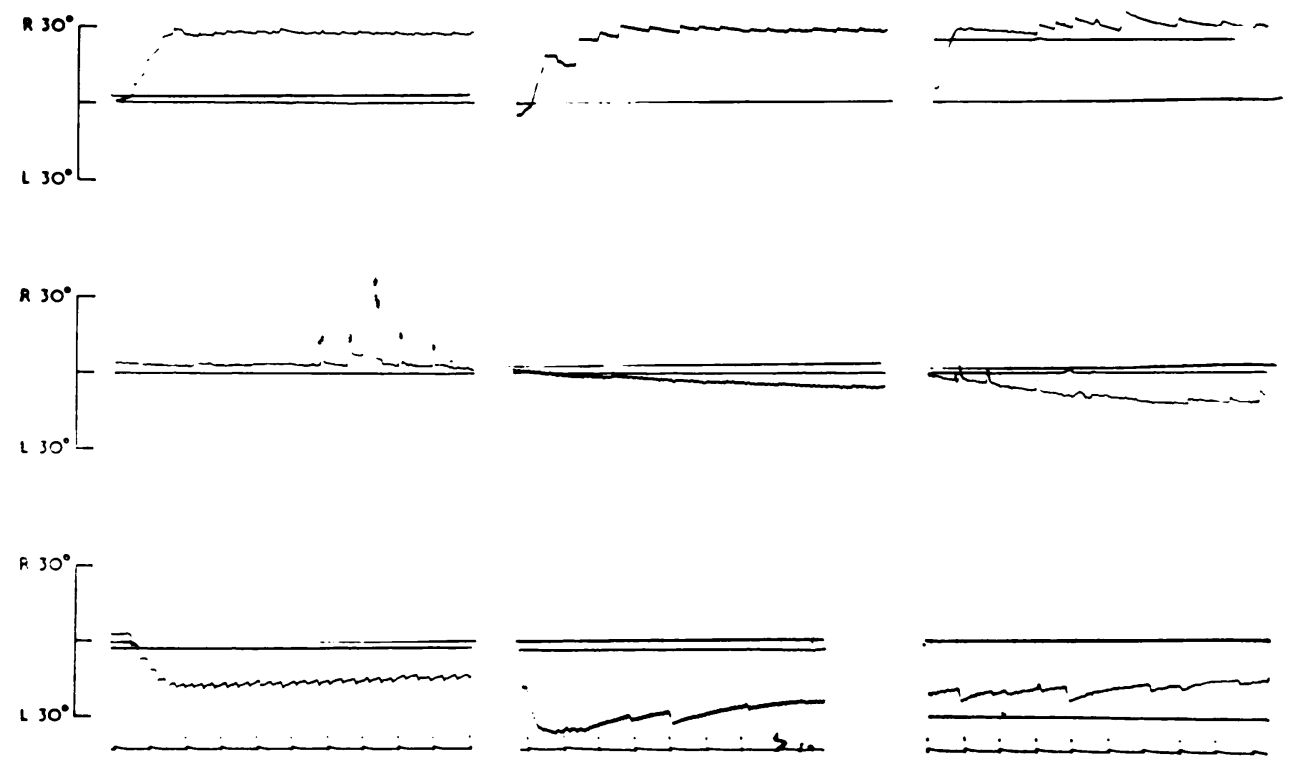

FIG. 3 Left acoustic neuroma. Subject G.C. Electronystagmographic tracings on the left (recorded in the presence of visual fixation) showed first degree spontaneous nystagmus to the right and left; the tracings in the middle (recorded when Frenzel's glasses were applied in darkness) showed increase in amplitude, decrease in velocity of the slow component, and irregularity in rhythm of the first degree spontaneous nystagmus to the right and left; the tracings on the right (recorded in darkness) showed a similar pattern to those in the middle. Time scale in seconds. 
The value of Frenzel's glasses in this situation is particularly worthy of note, since the nystagmus in question is typically rotational in character and cannot on this account be revealed electronystagmographically.

The condition is a notoriously distressing one and its diagnosis is therefore a matter of much importance (Harrison, 1966). The occurrence of the nystagmus needs to be observed and for this, as shown, Frenzel's glasses may be of unique value.

The authors would like to acknowledge with thanks the help and encouragement they have received from C. S. Hallpike, FRS.

\section{REFERENCES}

Dix, M. R. and Hallpike, C. S. (1966). Observations on the clinical features and neurological mechanism of spontaneous nystagmus resulting from unilateral acoustic $\bar{Q}$ neuro-fibromata. Acta Oto-laryng. (Stockh.), 61, 1-29.

Dix., M. R., Hallpike, C. S., and Hood, J. D. (1963). Electronystagmography and its uses in the study of spontaneous nystagmus. Trans. ophthal. Soc. U.K., 83, 531-557.

Frenzel, H. (1928). Der Nachweis von schwachen, beigewöhnlicher Beobachtung nicht Sichtbarem Spontan- क् nystagmus. Klin. Wschr., 7, 396-398.

Hallpike, C. S. (1967). Some types of ocular nystagmus and their neurological mechanisms. Proc. roy. Soc. Med., $\stackrel{2}{\overrightarrow{2}}$ 60, 1043-1054.

Harrison, M. Spencer (1964). Benign positional vertigo. In The Vestibular System and its Diseases, pp. 400-427. Edited by R. J. Wolfson. Pennsylvania Press.

Harrison, M. Spencer (1969). Vestibular neuronitis. Acta Oto-laryng. U.K., 67, 379-388.

Holmes, G. (1917). The symptoms of acute cerebellar injuries due to gunshot injuries. Brain, 40, 461-535.

Jongkees, L. B. W. (1969). Physiologie und Pathophysiologie des Vestibular organes. Arch. Ohr.-Nas.-u. Kehlk.-Heilk., क 194, 1-110.

\section{The April 1971 Issue}

\section{THE APRIL 1971 ISSUE CONTAINS THE FOLLOWING PAPERS}

Fast and slow twitch units in a human muscle R. E. P. SICA and A. J. MCCOMAS

Electrophysiological estimation of the number of motor units within a human muscle A. J. Mccomas, P. R. W. FAWCETT, M. J. CAMPBELL, and R. E. P. SICA

Electrophysiological study of dystrophia myotonica A. J. MCCOMAS, M. J. CAMPBELL, and R. E. P. SICA

Visual reactions in a case of long-lasting cortical blindness J. W. G. TER BRAAK, v. W. D. SCHENK, and A. G. M. VAN VLIET

Epidemiology of headache and migraine in women w. E. WATERS and P. J. o'CONNOR

Insulin induced hypoglycaemia in migraine JOHN PEARCE

Spontaneous intracerebral haemorrhage in patients suspected of multiple sclerosis I. F. ABROMS, L. YESSAYAN, J. SHILLITO, and C. F. BARLOW

Clinico-radiological study of collateral circulation after internal carotid and middle cerebral occlusion M. GADO and JOHN MARSHALL
Cockayne's syndrome: case report L. CROME and G. KANJILAL

Lymphocyte sensitization to nervous tissues and muscle in patients with the Guillain-Barré syndrome $\mathrm{E}$. A. CASPARY, S. CURRIE, J. N. WALTON, and E. J. FIELD

The syndrome of isolated epileptic status J. M. OXBURY and C. W. M. WHITTY

Motor neurone disease BHAGWAN SHAHANI, G. A. B. DAVIES-JONES, and W. RITCHIE RUSSELL

Performance on delayed response tasks by patients with Parkinsonism DAVID J. DE LANCY HORNE

Relation of hypermagnesaemia to activity and neuroleptic drug therapy in schizophrenic states C. J. BRACKENRIDGE and IVOR H. JONES

Book Reviews

Notice: Postal strike

Copies are still available from the PUBLISHING MANAGER, BRITISH MEDICAL ASSOCIATION, TAVISTOCK SQUARE, LONDON, WClH 9JR, price $£ 1.50$ 